RODRIGO CIPRIANO DOS SANTOS RISOLIA

\title{
Referibilidade na Condecine
}

\author{
Dissertação de Mestrado \\ Orientador Prof. Titular Dr. Luís Eduardo Schoueri
}

UNIVERSIDADE DE SÃO PAULO

FACULDADE DE DIREITO

SÃO PAULO - SP 
RODRIGO CIPRIANO DOS SANTOS RISOLIA

\section{Referibilidade na Condecine}

Dissertação apresentada à Banca Examinadora do Programa de PósGraduação em Direito, da Faculdade de Direito da Universidade de São Paulo, como exigência parcial para obtenção do título de Mestre em Direito, na área de concentração Direito Econômico, Financeiro e Tributário, sob a orientação do Prof. Titular Dr. Luís Eduardo Schoueri.

UNIVERSIDADE DE SÃO PAULO

FACULDADE DE DIREITO

SÃO PAULO - SP 
Autorizo a reprodução e divulgação total ou parcial deste trabalho, por qualquer meio convencional ou eletrônico, para fins de estudo e pesquisa, desde que citada a fonte.

Catalogação da Publicação

Serviço de Biblioteca e Documentação

Faculdade de Direito da Universidade de São Paulo

Risolia, Rodrigo Cipriano dos Santos

Referibilidade na Condecine / Rodrigo Cipriano dos Santos Risolia ; orientador Luís Eduardo Schoueri -- São Paulo, 2018.

$187 \mathrm{p}$.

Dissertação (Mestrado - Programa de Pós-Graduação em Direito Direito Econômico, Financeiro e Tributário) - Faculdade de Direito, Universidade de São Paulo, 2018.

1. Referibilidade. 2. Contribuições Especiais. 3. Contribuições de intervenção no domínio econômico. 4. Condecine - Contribuição para o Desenvolvimento da Indústria Cinematográfica Nacional. 5. Ancine. I. Schoueri, Luís Eduardo, orient. II. Título. 
Nome: RISOLIA, Rodrigo Cipriano dos Santos.

Título: Referibilidade na Condecine

Dissertação apresentada à Banca Examinadora do Programa de PósGraduação em Direito, da Faculdade de Direito da Universidade de São Paulo, como exigência parcial para obtenção do título de Mestre em Direito, na área de concentração Direito Econômico, Financeiro e Tributário, sob a orientação do Prof. Titular Dr. Luís Eduardo Schoueri.

\section{BANCA EXAMINADORA}

Prof. Titular Dr. Luís Eduardo Schoueri (Orientador) Instituição: FDUSP

Banca realizada em:

Resultado:

Banca Examinadora

Prof. Dr. Instituição:

Julgamento:

Assinatura:

Prof. Dr.

Instituição:

Julgamento:

Assinatura:

Prof. Dr.

Instituição:

Julgamento:

Assinatura: 
Dedico esse trabalho à Karina, por tudo o que passamos nesses últimos seis anos de relacionamento, ao Matheus e à Rosa Beatriz, por serem minha fonte de inspiração, e à minha mãe Alzira, que me ensinou a perseverar. 


\section{AGRADECIMENTOS}

Ao professor Luís Eduardo Schoueri, pela dedicação e paciência na orientação deste trabalho, pelo amor ao Direito Tributário refletido no empenho em ensiná-lo a seus alunos, pelos conselhos que recebi durante nosso convívio acadêmico e pelo exemplo de pessoa que é.

Aos professores Paulo Ayres Barreto e Humberto Ávila, pelas lições dadas em suas aulas e conselhos na qualificação desta dissertação, que certamente levarei para fora das Arcadas.

Ao professor Gerd Willi Rothmann, por ter me permitido iniciar a frequência na faculdade como aluno ouvinte, etapa fundamental do início de meu contato com esse ambiente acadêmico.

Ao brilhante Luciano Elias Reis, administrativista dessa nova geração que honra a academia paranaense, pela revisão do trabalho e considerações fundamentais, além de nossa antiga amizade dos tempos de Bom Jesus e III Milênio.

Aos srs. Hendrick Pinheiro da Silva, Ronaldo Apelbaum, Rafael Savassi, Carlos Augusto Daniel Neto, Fábio Goulart Tomkowski e Fábio Pellegrini, amigos que fiz nas salas de aula e no Porão, e que levarei para o resto da vida. De fato, no Largo de São Francisco é onde mora a amizade!

Aos srs. Mateus Calicchio Barbosa, Caio Takano, Henrique Coutinho, Maurício Fortes, Alexandre Evaristo Pinto, Leonardo Branco, Érico Pilatti, Rodolfo Tamanaha, Roberto Cordoniz, Raphael Lavez, Lucas Bevilaqua, Bruna Tapie Gabrielli, Clara Gomes Moreira e Guilherme Galdino, jovens tributaristas que participaram da minha trajetória acadêmica, e contribuíram de alguma forma com meu desenvolvimento.

Aos amigos de sempre, Alexandre Handar, André Santos, Daniel Gaideski, Felipe Spanholi, Gabriel Grube, Luiz Fernando Gonçalves, Márcio Moro, Rafael Carvalho Polli, Rafael Kula, Rafael Zaidowicz, Felipe e Rodrigo Zawadzki, a quem sempre poderei confiar.

À minha mãe Alzira, por tudo!

Ao meu padrasto, Fábio, por ter participado da minha criação. 
Às minhas irmãs Mariana e Camila, e minha sobrinha Giovanna. Todos vocês, por serem minha família!

Ao meu pai Marcos Risolia e ao avô André Risolia (in memoriam), pela nossa amizade.

À Karina, amor da minha vida, que esteve ao meu lado desde a seleção para o ingresso no mestrado até o final dessa dissertação, a quem devo muito por ter chegado aqui.

Ao Matheus, filho amado e companheiro, que suportou meu afastamento desde que decidi me tornar um mestrando.

À Rosa Beatriz, filha abençoada, que esteve comigo na fase final desse trabalho, ainda que fosse para me interromper nas madrugadas para alternar a minha ocupação entre livros e mamadeiras.

Obrigado. 
"É necessário que ao menos uma vez na vida você duvide, tanto quanto possível, de todas as coisas." (René Descartes) 


\section{RESUMO}

RISOLIA, Rodrigo Cipriano dos Santos. Referibilidade na Condecine. 2018. 183 p. Dissertação (Mestrado em Direito) - Faculdade de Direito, Universidade de São Paulo, São Paulo, 2018.

O objetivo da presente dissertação de mestrado é o de analisar a referibilidade na Contribuição para o Desenvolvimento da Indústria Cinematográfica Nacional - Condecine, instituída pela Medida Provisória no 2.228-1/2001. Considera-se a referibilidade indireta como requisito das contribuições de intervenção no domínio econômico - Cides. A Condecine é um conjunto de três Cides: Título, Remessa e Teles. A Condecine Título é devida pelos titulares de direito de exploração de obras audiovisuais nos diversos segmentos citados em lei. A Condecine Remessa é devida pelos pagadores de rendimentos de exploração de direito autoral de obra audiovisual ao exterior. A Condecine Teles tem como contribuintes empresas permissionárias, concessionárias e autorizadas de serviços que, de maneira geral, possam distribuir conteúdo audiovisual na forma da Lei de Acesso Condicionado. No primeiro capítulo são segregadas as espécies tributárias e conferida autonomia às contribuições especiais, caracterizadas por serem vinculadas à atuação estatal referida a grupo que recebe sua prestação ou que acarreta despesa especial. Os indivíduos integrantes desse grupo são os sujeitos legítimos a figurar como respectivos contribuintes. No segundo capítulo, discorre-se sobre a contribuição de intervenção no domínio econômico - uma das espécies de contribuição especial - pelo papel que desempenha na atuação estatal. Posto isso, trata-se do controle das Cides pelo postulado da proporcionalidade, que demonstrou ser desproporcional dirigir tais contribuições a grupo não afetado pela atuação estatal financiada pelo tributo, bem como o tratamento igualitário de indivíduos que com ela se relacionam de forma distinta. No terceiro capítulo analisa-se a jurisprudência, para se concluir que os tribunais brasileiros não apresentam entendimento pacífico quanto à referibilidade indireta como requisito das Cides, ou mesmo parâmetros para sua delimitação, o que reforça a importância das conclusões parciais do primeiro capítulo no estabelecimento de pilares para avaliar a referibilidade indireta na Condecine. Por fim, no quarto capítulo, discorre-se sobre a intervenção da União no segmento audiovisual, a destinação do produto da arrecadação das contribuições em exame e a referibilidade nas três modalidades da Condecine. Conclui-se que a referibilidade indireta é respeitada na Condecine Título, desde que sejam oneradas somente as obras audiovisuais comerciais, e não as publicitárias. Não há conteúdo previsto para caracterização de obra audiovisual, podendo representar obras musicais. Igualmente é respeitada na Condecine Remessa. Entretanto, na Condecine Teles, apenas se respeita à referibilidade indireta quando se tributa o serviço público condicionado (televisão por assinatura), uma vez que são obrigados a produzir e distribuir obras audiovisuais nacionais. Os serviços de telecomunicação multimídia e telefonia, apesar de permitirem distribuição de conteúdo audiovisual por meio de redes como a internet, não fazem parte do segmento econômico do audiovisual, representando apenas outro segmento que, mutuamente, produz e recebe benefícios do segmento afetado.

Palavras-chave: Referibilidade. Contribuições Especiais. Contribuições de intervenção no domínio econômico. Condecine - Contribuição para o Desenvolvimento da Indústria Cinematográfica Nacional. Ancine - Agência Nacional do Cinema. 


\begin{abstract}
RISOLIA, Rodrigo Cipriano dos Santos. Tax referability for Condecine. 2018. 183 p. Dissertação (Mestrado em Direito) - Faculdade de Direito, Universidade de São Paulo, São Paulo, 2018.
\end{abstract}

The purpose of this dissertation is to analyze tax allocation within the so-called CONDECINE - Contribuição para o Desenvolvimento da Indústria Cinematográfica Nacional (Contribution to the Development of the National Film Industry), instituted by Provisional Measure n. 2228-1/2001. Indirect tax allocation is considered as a requirement of intervention contributions in the economic domain - Cides. CONDECINE is a set of three Cides: Title, Remittance and Teles. CONDECINE Title is due by the holders of the right to explore audiovisual works in the several segments listed in the law. CONDECINE Remittance is due by the payers of income from exploration of copyrights of audiovisual works abroad. CONDECINE Teles encompasses "permitted companies" (permissionárias), concessionaires and authorized services as taxpayers, which can generally distribute audiovisual contents in the form of Law n. 12.485/2001. In the first chapter, tributary species are segregated, and autonomy is granted to special contributions, characterized by being linked to the state action referred to the group that receives their benefit or that entails special expenses. The individuals who belong to this group are the legitimate subjects to appear as their respective contributors. In the second chapter, one of the modalities of special contributions (the contribution of intervention in the economic domain) is analyzed by the role it plays in the state action. Given this, it is approached about Control of Cides by the postulate of proportionality, that it has shown that it is disproportionate to direct such contributions to a group that is not affected by the state performance financed by taxation, as well as the equal treatment of individuals who are affected in a different way. In the third chapter, jurisprudence was analyzed in order to conclude that the Brazilian courts do not present a peaceful agreement regarding indirect allocation as a requirement of the Cides, or even parameters for its delimitation, which reinforces the importance of the partial conclusions of the first chapter in establishing pillars to assess indirect tax referability in CONDECINE. Lastly, in the fourth chapter, the intervention of the Union in the audiovisual segment, the destination of the product from the collection of the contributions under examination, and the referability in the three CONDECINE modalities are discussed. It is concluded that indirect referendum is approached in the CONDECINE Title, provided that only audiovisual commercial works, and not advertising, are charged. There is no content intended for the characterization of audiovisual works, and they may include musical works. That is also approached in CONDECINE Remittance. However, in CONDECINE Teles, indirect tax referability is only approached when the conditional public service (pay-TV) is taxed, since they are obliged to produce and distribute national audiovisual works. While allowing the distribution of audiovisual contents through networks such as the Internet, multimedia and telephone telecommunication services are not part of the economic segment of the audiovisual sector, thus representing only another segment that mutually produces and receives benefits from the affected segment.

Keywords: Tax referability. Special Contributions. Contributions of intervention in the economic domain. Condecine - Contribution to the Development of the National Film Industry. Ancine - National Cinema Agency. 


\section{LISTA DE ABREVIATURAS}

ADI

AFRMM

Anatel

Ancine

ATP

BNDES

Carf

CBT

Cebrae

CF

Cide

Condecine

Cosip

CPC

CTN

DF

DIP

EC

Embrafilme

FNC

FSA

Funrural

Fust

Gera

Ibra

Incra

Inda

INSS

LSAC

NCPC

Ação Direta de Inconstitucionalidade

Adicional ao Frete para Renovação da Marinha Mercante

Agência Nacional de Telecomunicações

Agência Nacional do Cinema

Adicional de Tarifa Portuária

Banco Nacional do Desenvolvimento Social

Conselho Administrativo de Recursos Fiscais

Código Brasileiro de Telecomunicações

Centro Brasileiro de Apoio à Pequena e Média Empresa

Constituição Federal

Contribuição de Intervenção no Domínio Econômico

Contribuição para o Desenvolvimento da Indústria

Cinematográfica Nacional

Contribuição para o Custeio do Serviço de Iluminação Pública

Código de Processo Civil

Código Tributário Nacional

Distrito Federal

Departamento de Imprensa e Propaganda

Emenda Constitucional

Empresa Brasileira de Filmes

Fundo Nacional da Cultura

Fundo Setorial do Audiovisual

Fundo de Assistência ao Trabalhador Rural

Fundo de Universalização dos Serviços de Telecomunicações

Grupo Executivo da Reforma Agrária

Instituto Brasileiro de Reforma Agrária

Instituto de Colonização e Reforma Agrária

Instituto Nacional do Desenvolvimento Agrário

Instituto Nacional da Seguridade Social

Lei de Acesso Condicionado

Novo Código de Processo Civil 
Portobrás

Prodav

Prodecine

Proinfra

RE

REsp

Sebrae

Senac

Senai

Sesc

Sesi

Sinditelebrasil

SSR

STF

STJ

Supra

TRF

Vod
Empresa dos Portos do Brasil S/A

Programa de Apoio do Desenvolvimento Audiovisual

Programa de Apoio ao Desenvolvimento do Cinema Brasileiro

Programa de apoio ao desenvolvimento da Infraestrutura

Recurso Extraordinário

Recurso Especial

Serviço de Apoio às Micro e Pequenas Empresas Brasileiras Serviço Nacional de Aprendizagem Comercial

Serviço Nacional de Aprendizagem Industrial

Serviço Social do Comércio

Serviço Social da Indústria

Sindicato Nacional das Empresas de Telefonia e do Serviço Móvel e Pessoal

Serviço Social Rural

Supremo Tribunal Federal

Superior Tribunal de Justiça

Superintendência de Reforma Agrária

Tribunal Regional Federal

Video on demand 


\section{SUMÁRIO}

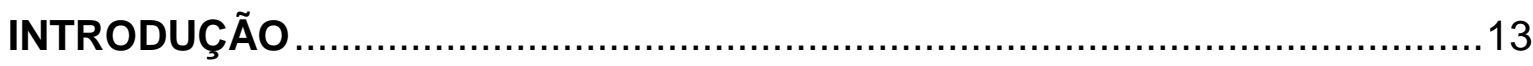

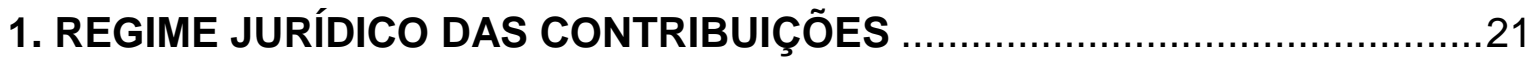

1.1 CLASSIFICAÇÃO DAS ESPÉCIES TRIBUTÁRIAS .................................21

1.1.1 As correntes dicotômica e tricotômica ...........................................22

1.1.2 Insuficiência das classificações dicotômica/tricotômica e as

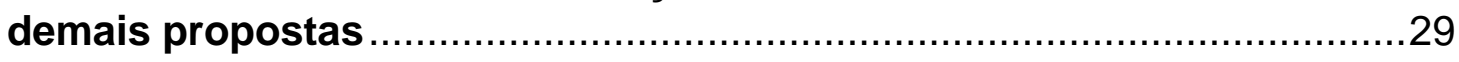

1.2 CONTRIBUIÇÕES COMO TRIBUTOS FINALÍSTICOS E A NECESSÁRIA

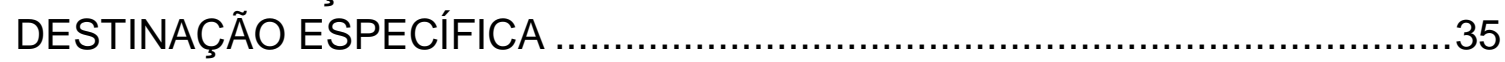

1.3 DISTINÇÃO ENTRE AS CONTRIBUIÇÕES .............................................41

1.4 DESVINCULAÇÃO DA MATERIALIDADE DAS CONTRIBUIÇÕES

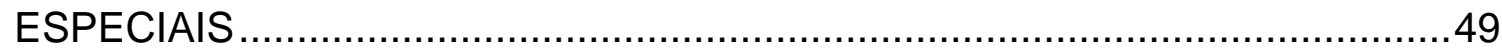

1.5 CONSIDERAÇÕES PARCIAIS SOBRE AS CONTRIBUIÇÕES ...................54

2. CONTRIBUIÇÃO DE INTERVENÇÃO NO DOMÍNIO ECONÔMICO ...............57

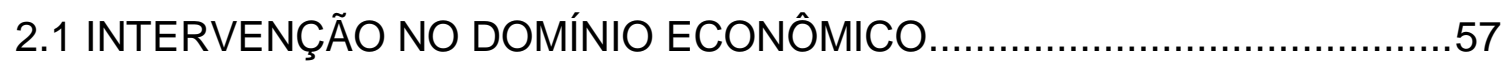

2.1.1 Normas programáticas e Ordem Econômica ....................................57

2.1.2 Conceito de intervenção no domínio econômico ...............................61

2.1.3 Modalidades de intervenção no domínio econômico.......................64

2.2 O PAPEL DESEMPENHADO PELAS CIDES NA INTERVENÇÃO NO

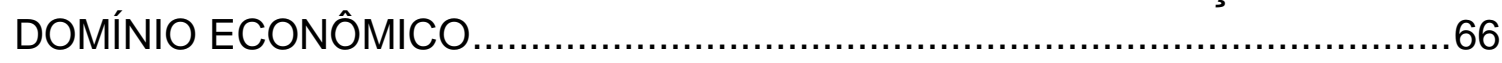

2.3 CONTROLE DAS CIDES PELA PROPORCIONALIDADE .........................75

2.3.1 O postulado da proporcionalidade ………...................................

2.3.2 As três fases da proporcionalidade ............................................. 80

2.3.3 Proporcionalidade nas contribuições de intervenção no domínio econômico

2.4 CONSIDERAÇÕES PARCIAIS SOBRE A CONTRIBUIÇÃO DE INTERVENÇÃO NO DOMÍNIO ECONÔMICO

3. A REFERIBILIDADE DAS CONTRIBUIÇÕES NA JURISPRUDÊNCIA BRASILEIRA.

3.1 CONTRIBUIÇÃO AO SEBRAE PREVISTA NO ART. 8ำ, § 3ํDA LEI №

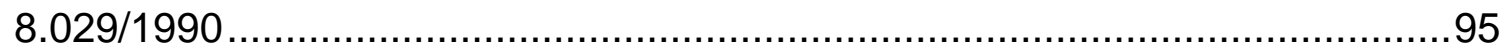

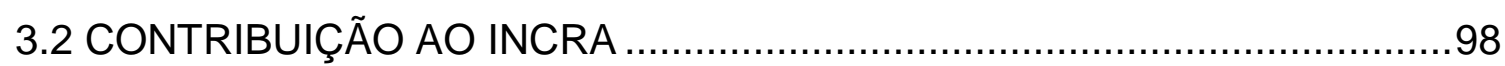

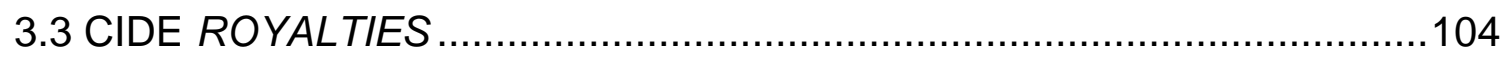

3.4 ADICIONAL AO FRETE PARA A RENOVAÇÃO DA MARINHA MERCANTE

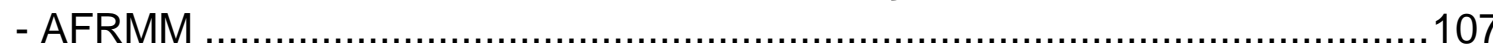

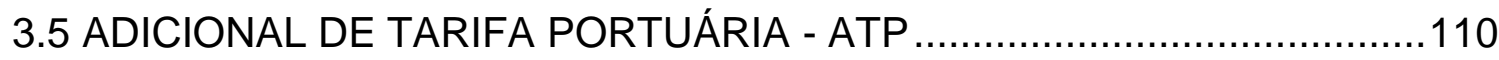


3.6 CONTRIBUIÇÃO AO SEBRAE DEVIDA POR ENTIDADE SEM FINS LUCRATIVOS.

3.7 CONTRIBUIÇÃO AO FUNDO DE UNIVERSALIZAÇÃO DOS SERVIÇOS

DE TELECOMUNICAÇÕES - FUST ....................................................113

3.8 CONTRIBUIÇÃO PARA O FOMENTO DA RADIODIFUSÃO PÚBLICA....115

3.9 REFERIBILIDADE EM OUTRAS CONTRIBUIÇÕES ESPECIAIS .............118

3.9.1 Anuidades de Conselhos Profissionais de Fiscalização ...............118

3.9.2 Contribuições ao regime próprio de previdência e custeio de prestação de serviços de assistência à saúde do servidor público ......120

3.10 CONCLUSÕES PARCIAIS SOBRE A REFERIBILIDADE INDIRETA NA JURISPRUDÊNCIA

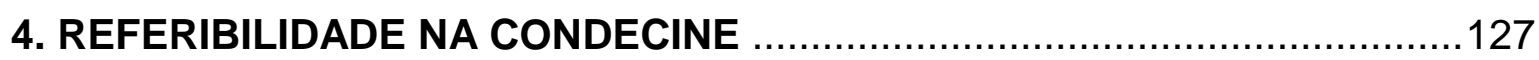

4.1 HISTÓRICO NORMATIVO - DA POLÍTICA DO GOVERNO PROVISÓRIO À

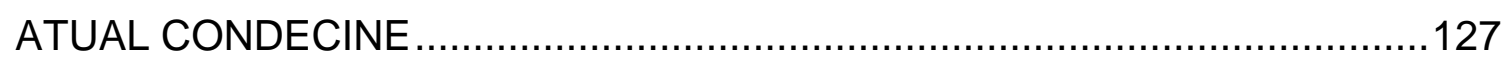

4.2 O PAPEL DA ANCINE NA POLÍTICA NACIONAL DO CINEMA ...............131

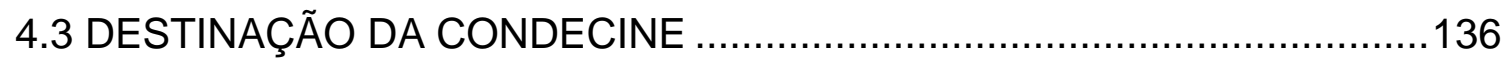

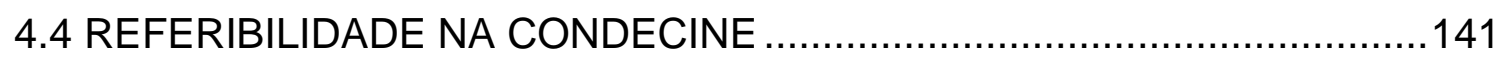

4.4.1 Referibilidade na Condecine Título ...........................................141

4.4.2 Referibilidade na Condecine Remessa .........................................148

4.4.2.1 Bis in idem da Condecine e Cide Royalties ................................150

4.4.3 Referibilidade na Condecine Teles ............................................155

4.4.3.1 Perspectiva de tributação dos serviços de vídeo sob demanda e a sucumbência da Condecine Teles sobre serviços de telefonia e internet.165 


\section{INTRODUÇÃO}

Examina-se neste trabalho a Condecine, com as seguintes considerações iniciais. Contribuição de intervenção no domínio econômico que é, o tributo - ou o conjunto de três contribuições, como adiante é demonstrado -, que há pouco não recebia tanta atenção como outras Cides, tem se tornado objeto de discussões no âmbito judicial e político, uma vez que objetiva o custeio da intervenção no segmento audiovisual, envolvendo interesses de todas as cadeias de produçãodistribuição do setor.

É válido dizer que a atividade cultural no Brasil dificilmente será lucrativa sem o apoio estatal. Para que se tenha um projeto cultural lucrativo, no caso, obra audiovisual, normalmente deve-se buscar atingir o grande público consumidor. Com isso, obras regionais, por exemplo, são desprestigiadas pelos agentes econômicos, o que reduz a diversidade das manifestações culturais no País.

Se for considerado que a Constituição tanto valora a cultura nacional quanto a atividade econômica que desempenhe sua função social, é adequado que o Estado institua políticas públicas que favoreçam atuação de agentes econômicos que produzam, em última análise, bens culturais. Até então nada há de muito polêmico nisso, não há quem sustente por argumentos sérios que o Estado não deva fomentar a cultura. Os problemas começam quando se questiona a quem incumbe os custos dessa atuação.

O Estado brasileiro promete muito por meio de sua Constituição, mas nem sempre as necessidades públicas são satisfeitas. Demanda-se do Estado o compromisso com diversos gastos, como juros da dívida pública, salários do funcionalismo, previdência, investimento em infraestrutura, saúde, educação e segurança pública, para dizer o mínimo. Dada a escassez dos recursos, não se pode promover a cultura como o interesse público demanda. Não obstante, devese ressaltar o problema levantado por José de Ribamar Caldas Furtado, no sentido de que a importância dos impostos, cujas receitas não são vinculadas, é a de permitir liberdade ao elaborador das políticas públicas, que poderá alocar os recursos em conformidade com o planejamento adequado ao respectivo tempo e espaço, que se ajusta à realidade de cada ente tributante. Como há diversas exceções constitucionais ao princípio da não vinculação dos impostos, apenas 
$5,7 \%$ (cinco pontos e sete décimos percentuais) do orçamento estão livres da vinculação de receitas, o que compromete "o encadeamento dos elementos que constituem as chamadas funções do administrador, [..]: previsão, organização, comando, coordenação e controle."1

A busca por instrumentos de captação de recursos é contínua, e, no caso da produção de obras audiovisuais, para financiar a intervenção no domínio econômico objetivando o desenvolvimento incentivado do setor, foi instituída a Condecine pela Medida Provisória no 2.221-8/2001.

A instituição de uma Cide para o custeio de intervenção no domínio econômico é, antes de tudo, medida que respeita a justiça tributária. Se há atuação estatal que atinja de forma especial a certo grupo, é razoável que seja custeada por ele. Por outro lado, considerando a permanente necessidade de recursos do Estado, cada vez mais se busca o financiamento de sua atividade através de tributos vinculados, ressaltando a importância do estudo de seus contornos no contexto de um sistema constitucional de rígida distribuição de competências.

Em crítica contundente, Marco Aurélio Greco revela perplexidade pela proliferação das contribuições de intervenção no domínio econômico "como se fosse uma panaceia para a necessidade de recursos financeiros para a União. Onde houver necessidade de recursos, cria-se uma Cide". Mesmo sem deixar de reconhecer que a atividade estatal precisa ser custeada, exclama contra a insuficiência dos critérios de controle dessa espécie tributária. ${ }^{2}$ Essa dissertação versa, essencialmente, sobre um dos critérios de controle das Cides, a referibilidade indireta relacionada à Condecine.

De maneira geral, propõe-se responder se é legítima a cobrança da Condecine dos indivíduos postos como contribuintes pela Medida Provisória, ou se ela se trata de um instrumento de arrecadação que nada respeita os critérios identificados no sistema constitucional vigente. Esse é o objetivo da pesquisa.

Argumentos políticos sobre a sua cobrança não faltam. Se os pequenos agentes econômicos defendem o incentivo e o seu custeio pela contribuição, grandes produtores e empresas de telecomunicação se insurgem contra sua

\footnotetext{
${ }^{1}$ FURTADO, José de Ribamar Caldas. O problema da vinculação de recursos orçamentários. Revista do TCU, Brasília, n. 111, p. 63-72, jan./abr. 2008. p. 66.

2 GRECO, Marco Aurélio. Em busca do controle sobre as Cides. Revista do Advogado, São Paulo, p. 101-118, 2007. p. 101.
} 
cobrança. Essa divergência é natural e saudável em um sistema democrático. A tarefa proposta é trazer um pouco de luz sobre o problema jurídico aqui apresentado.

Uma explicação preliminar é necessária. Condecine é, na realidade, um conjunto de três contribuições de intervenção no domínio econômico: Título, Remessa e Teles.

A primeira incide sobre "a veiculação, a produção, o licenciamento e a distribuição de obras cinematográficas e videofonográficas com fins comerciais" (art. 32, I) e "a veiculação ou distribuição de obra audiovisual publicitária incluída em programação internacional [...] nos casos em que existir participação direta de agência de publicidade nacional" (art. 32, II). São os contribuintes, no primeiro caso, os detentores do direito de licenciamento e exploração comercial, e no segundo, o representante legal da programadora estrangeira no País (art. 35, I e II).

A segunda incide sobre "o pagamento [de maneira geral], aos produtores, distribuidores ou intermediários no exterior, de importâncias relativas a rendimento decorrente da exploração de obras cinematográficas e videofonográficas ou por sua aquisição ou importação" (art. 32), parágrafo único, e tem como contribuinte o responsável pelo pagamento (em sentido amplo), conforme art. 35, III.

A terceira incide sobre "a prestação de serviços que se utilizem de meios que possam, efetiva ou potencialmente, distribuir conteúdos audiovisuais nos termos da lei que dispõe sobre a comunicação audiovisual de acesso condicionado" (art. 32, II) e tem como contribuintes "as concessionárias, permissionárias e autorizadas de serviços de telecomunicações" (art. 35, IV).

Para responder se a referibilidade indireta é respeitada nessas três contribuições, indispensável delimitar a atuação da União no segmento audiovisual, e discorrer o papel dessa Cide na intervenção no domínio econômico.

Não apenas isso, a própria referibilidade indireta não é pacífica na doutrina e na jurisprudência, e mesmo os que a consideram, podem compreendê-la sob diversas formas. Assim, é necessário, para complementar o exame, responder como as Cides se distinguem das demais espécies tributárias, e de que modo se considera a referibilidade indireta. 
Essa tarefa partirá das seguintes premissas. Em primeiro lugar, entende-se que as contribuições do art. 149 possuem natureza tributária por se amoldarem, obviamente, ao conceito de tributo extraído da Constituição. Trabalha-se esse ponto porque Marco Aurélio Greco pôs em cheque a natureza jurídica das contribuições do art. 149 da Constituição, ao sustentar que elas apenas receberiam o regime jurídico tributário parcialmente, posto que o caput desse dispositivo determina a observância apenas dos arts. 146, III, e 150, I e III, afastando a incidência do princípio da igualdade tributária, vedação ao confisco, limitações ao tráfego e imunidades, todos do art. 150, incisos II, IV, V e VI. Teriam apenas o regime jurídico equiparado ao dos tributos. ${ }^{3}$

Não é essa a posição que se adota. Há um conceito de tributo extraído da Constituição, que se alinha ao trazido no art. 3 do CTN, elucidado por Geraldo Ataliba como: "obrigação jurídica pecuniária, ex lege, que não se constitui em sanção de ato ilícito, cujo sujeito ativo é pessoa pública (ou delegado por lei desta) e cujo sujeito passivo é alguém nessa situação posto pela vontade da lei, obedecidos os desígnios constitucionais (implícitos ou explícitos)." ${ }^{4}$

A questão há muito deixou de ser um problema prático em razão do entendimento do STF exarado no RE $146.733,{ }^{5}$ que tratou da Contribuição Social sobre o Lucro Líquido, e seguiu pela natureza tributária das contribuições, orientação que se mantém inalterada. Se a própria Constituição excetua a aplicação de certas normas inerentes aos demais tributos às contribuições, isso de modo algum as desnatura. Mesmo a atribuição da capacidade tributária a outra pessoa que não o titular da competência tributária não lhes altera a referida natureza. ${ }^{6}$

${ }^{3}$ GRECO, Marco Aurélio. Contribuições (uma figura sui generis). São Paulo: Dialética, 2000. p. 73-74.

${ }^{4}$ ATALIBA, Geraldo. Hipótese de Incidência Tributária, 6. ed. São Paulo: Malheiros, 2009. p. $32-$ 34. Observe-se a posição mais precisa de Humberto Ávila, que defende que o conceito de tributo pode ser construído na Constituição, considerando as normas que tratam do Sistema Tributário, ou através dela, pelos instrumentos legais que a própria confere à conceituação de tributo, no caso, a Lei Complementar, conforme art. 146. (As Contribuições no Sistema Tributário Brasileiro. In: ROCHA, Valdir de Oliveira. (Coord.). Grandes Questões Atuais de Direito Tributário. São Paulo: Dialética, 2003. p. 315.

${ }^{5}$ BRASÍLIA, Supremo Tribunal Federal. Recurso Extraordinário ํㅜ 146.733, Relator Ministro Moreira Alves, Plenário, decisão unânime, publicado em 06/11/1992.

6 OLIVEIRA, Regis Fernandes. Curso de Direito Financeiro, 7. ed. São Paulo: Revista dos Tribunais, 2015. p. 311. 
Apesar de se compreender o conceito de tributo como jurídico e fundado na Constituição, não se ignora que ele e suas espécies têm inspiração na Ciência das Finanças. Como assenta Gian Antonio Micheli, se por um lado é impossível não considerar a norma tributária como produto técnico-econômico-jurídico, é também inviável ignorar que as normas tributárias disciplinam fenômenos para além do âmbito normativo, sendo que essa dimensão influencia a respectiva interpretação e aplicação. Se é cediço que o legislador, ao elaborar a norma tributária, é influenciado por considerações de oportunidade e conveniência, em razão de circunstâncias técnicas e econômicas que repousam seus fundamentos na Ciência das Finanças, deve o juiz buscar nesta os juízos de valor para aplicar a norma ao caso concreto, de modo que há relação de complementaridade entre a Ciência das Finanças e o Direito. ${ }^{7}$

Por fim, sem estender muito à clássica discussão da autonomia do Direito Tributário (ou de qualquer ramo do Direito), defende-se que essa autonomia não deve ser considerada com rigor, conforme as breves considerações adiante, que aqui são justificadas. A compreensão das contribuições de intervenção no domínio econômico obriga que o jurista se volte para além da hipótese de incidência e base de cálculo do tributo. É uma espécie tributária naturalmente muito mais complexa do que os impostos e as taxas, como se verá. E, para seu estudo, abandona-se a ideia de investigar as normas de Direito Tributário separadamente do Direito Financeiro e Administrativo, como é perceptível pela própria estruturação deste trabalho.

Apresentam-se alguns autores que dão suporte a essa premissa. Paulo de Barros Carvalho alude à obrigatoriedade da consideração da unidade do sistema jurídico para afastar a autonomia, ainda que didática, do Direito Tributário. A ordenação jurídica, segundo o autor, é una e inseparável, de modo que as normas seriam relacionadas por vínculos hierárquicos e relações de coordenação, tornando tarefa impossível conhecer as regras isoladamente sem a observância do sistema em sua integralidade. A unidade do sistema jurídico permitiria, quando muito, 0 agrupamento de normas de diversos níveis e setores em uma mancha no sistema,

\footnotetext{
7 MICHELI, Gian Antonio. Curso de Direito Tributário. Tradução de Marco Aurélio Greco e Pedro Luciano Marrey Jr. - São Paulo: Revista dos Tribunais, 1978. p. 12-13.
} 
de impossível demarcação rigorosa e definitiva. ${ }^{8}$ Em sentido semelhante seguem Luciano Amaro ${ }^{9}$ e Sacha Calmon Navarro Coêlho. ${ }^{10}$

Hugo de Brito Machado Segundo acrescenta que é necessário distinguir a própria ciência jurídica de seu objeto, o direito posto. $\mathrm{O}$ objeto da ciência seria indivisível, enquanto a ciência comportaria "separações" ou "departamentalizações". Esse fenômeno é conhecido nas diversas ciências, que é a especialização, ou seja, um movimento de conhecimento de parcelas da realidade e que não têm existência independente do todo que integram ${ }^{11}$.

$O$ argumento da especialização mostra-se preciso e colmata a unicidade do Direito. Um mesmo instituto pode ser apreciado sob diferentes ramos do direito com a mesma conformação. Ainda que se diga que determinado ramo possui autonomia legislativa, científica ou didática, essa autonomia sempre será relativa, vez que depende de estruturação dos demais ramos para ser compreendida. ${ }^{12}$ Logo, não há como falar de Cide exclusivamente sob preceitos do Direito Tributário.

Para atingir o objetivo proposto, adotou-se o seguinte plano de trabalho. No Capítulo 1 trilhou-se o caminho percorrido pela doutrina e jurisprudência, apontando as diversas classificações das espécies tributárias no intuito de delineá-las e isolar as contribuições de intervenção no domínio econômico, facilitando sua compreensão. Identificadas as contribuições do art. 149 da Constituição, versou-se sobre sua finalidade e destinação, requisitos próprios dessa "espécie"13 tributária. Ainda buscando esclarecer o delineamento das contribuições, todas as suas espécies foram comparadas, evidenciando-se as contribuições especiais, que se dividem em contribuições no interesse das categorias profissionais ou econômicas e contribuições de intervenção no domínio econômico. Nas contribuições especiais a referibilidade indireta foi definida como requisito da espécie.

A referibilidade indireta precisou ser elucidada, pois parte da doutrina entende que é a materialidade da hipótese de incidência que deve representar atuação estatal, enquanto outra parte defende que a vinculação é requisito das

${ }^{8}$ CARVALHO, Paulo de Barros. Curso de Direito Tributário, 23. ed. São Paulo: Saraiva, 2011. p. 46.

9 AMARO, Luciano. Direito tributário brasileiro, 21. edição. São Paulo: Saraiva, 2016. p. 30.

10 COÊLHO, Sacha Navarro. Curso de Direito Tributário Brasileiro, 15. ed. Rio de Janeiro:

Forense, 2016. p. 29.

11 MACHADO SEGUNDO, Hugo de Brito. Primeiras Linhas de Direito Tributário e Financeiro:

Material e Processual, 8. ed. Atlas: São Paulo, 2014. p. 7.

12 AMARO, Luciano. Op. Cit. p. 31.

${ }^{13}$ Não se pretende adiantar, neste ponto, a classificação adotada. 
contribuições especiais, mas não da materialidade da hipótese de incidência. Com esses esclarecimentos, é possível avançar para o exame das Cides.

No Capítulo 2, as Cides foram analisadas como instrumento da intervenção econômica. Assim, discorreu-se sobre a própria intervenção no sistema constitucional, as modalidades de intervenção, e, finalmente, o papel das Cides nesse contexto, para delinear o custeio da atuação interventiva, e a possibilidade de a Cide representar intervenção enquanto norma indutora de comportamento do contribuinte. Passo seguinte foi a investigação do controle das Cides pela proporcionalidade, uma vez que, em sendo instrumento da intervenção (ou até mesmo a própria intervenção), é preciso regulá-la sob critérios jurídicos objetivos que garantam o atingimento de sua finalidade. O manejo das Cides de forma desproporcional pode representar sua desnaturação, seja pela cobrança de carga tributária excessiva, seja pela tributação de indivíduos não pertencentes ao grupo afetado pela atuação estatal, desrespeitando a referibilidade indireta. Uma noção de referibilidade indireta foi esclarecida, não necessariamente confirmada pela jurisprudência.

Alguns dos principais precedentes que tratam da referibilidade indireta nas contribuições especiais, majoritariamente de Cides, são relatados e criticados no Capítulo 3. O objetivo é tentar elucidar se há orientação dos tribunais para o conceito de referibilidade indireta, bem como o seu reconhecimento enquanto requisito das contribuições especiais.

Adentrando ao ponto central da dissertação, para responder se as três contribuições que formam o conjunto da Condecine respeitam a referibilidade indireta, inicialmente se discorreu sobre a intervenção da União no setor do audiovisual. Foram expostos breves apontamentos histórico-normativos da atuação nesse setor, para chegar no sistema atual. Assim, demonstrou-se a competência da Ancine, a destinação da Condecine, e, por fim, foi analisada a referibilidade nas três espécies da contribuição, Título, Remessa e Teles. 


\section{CONSIDERAÇÕES FINAIS}

A presente dissertação se voltou à solução do atendimento à referibilidade indireta nas contribuições Condecine Título, Teles e Remessa.

O exame do respeito à referibilidade indireta implica aferir se os contribuintes de contribuição especial pertencem a grupo afetado pela atuação estatal financiada pelo tributo, com o objetivo de se conferir legitimidade a instituição da contribuição especial.

As contribuições especiais se destacam como espécie autônoma de tributo em contexto de distribuição rígida de competência tributária na Constituição. São cobradas de grupo delimitado e afetado pela atuação custeada pelo próprio tributo. Apesar de serem classificadas como tributos vinculados, sua vinculação não necessariamente reside na materialidade da hipótese de incidência. São entendidas como vinculadas porque a atuação estatal financiada pelas contribuições é pressuposta.

Dividem-se em contribuições no interesse das categorias econômicas ou profissionais e contribuições de intervenção no domínio econômico, e são classificadas ao lado das contribuições sociais. Enquanto nas contribuições especiais identifica-se o requisito de validade da referibilidade indireta, ou seja, a contribuição serve de custeio da atuação estatal dirigida a grupo de contribuintes ou em razão de sua atividade, as contribuições sociais apenas se diferem dos impostos apenas pela afetação de seus recursos à Seguridade Social. Ambas são previstas no art. 149 da Constituição e representam tributos finalísticos, e, por conta disso, a destinação de seus recursos deve ser direcionada às respectivas áreas de cada (sub)espécie.

Especificamente sobre as contribuições de intervenção no domínio econômico, evidenciou-se que seu papel interventivo pode ser o de financiar a atuação estatal direta de serviços monopolísticos não caracterizados como essencialmente públicos, mas não os que se submetem a regime de concorrência com a iniciativa privada. Podem também financiar a atuação indireta do Estado como "agente normativo e regulador da atividade econômica", no âmbito das funções de fiscalização e incentivo. E, além disso, poderia a Cide ser representar a própria intervenção, enquanto norma tributária indutora, desde que dirigida ao 
grupo de contribuintes afetado pela atuação estatal igualmente custeada pelo tributo, e que o produto da arrecadação esteja limitado, ainda que estimativamente, ao custo da atuação estatal.

Por força do postulado da proporcionalidade, é possível exercer o controle das Cides. Pela proporcionalidade é que se permite o controle da relação entre a intervenção promovida e a finalidade objetivada, especialmente no caso das normas indutoras, uma vez que somente é possível a indução no sentido da intervenção. Não apenas isso, por meio desse postulado, há o controle da eleição do grupo de contribuintes que, obrigatoriamente, deve ser determinado pela lei em razão de serem afetados pela atuação estatal. A carga fiscal suportada pelo grupo, igualmente, deve respeitar a proporcionalidade, não sendo válida a arrecadação em patamar superior ao do custo da atuação estatal. Por fim, em sendo possível identificar contribuintes dentro do grupo que sejam atingidos pela atuação estatal, ou a provoquem, em maior intensidade, podem arcar com tributação superior aos demais indivíduos do grupo.

Muito embora a referibilidade indireta tenha sido bem delineada neste trabalho, a jurisprudência brasileira não confirma ou infirma as conclusões aqui apresentadas. Apesar de o Judiciário ter examinado a referibilidade em alguns precedentes, nota-se que os mesmos não indicam critérios seguros para afirmar: a) se a referibilidade indireta é requisito das contribuições especiais; e b) de que forma se evidencia a referibilidade indireta. $\mathrm{Na}$ tentativa de sustentar harmonia da jurisprudência, alguns precedentes são citados em outras decisões que, muitas vezes, divergem entre si. Espera-se que o STF, único tribunal superior competente para tanto, resolva essas questões em definitivo.

Expostas essas considerações conclusivas preliminares, passa-se a responder o problema posto desta pesquisa, ou seja, o respeito à referibilidade indireta nas contribuições que compõem a Condecine.

A intervenção estatal no segmento audiovisual remonta à década de 1930, sendo que o sistema atual é marcado pela Medida Provisória no 2.228-1/2001, que instituiu a Política Nacional do Cinema e estruturou o Conselho Superior de Cinema e a Agência Nacional de Cinema. Também instituiu as contribuições que compõem o grupo Condecine: Título, Remessa e Teles.

Sendo assim, o exame da destinação legal da arrecadação fez-se necessário. O texto original da Medida Provisória oㅡ 2.228-1/2001 estabelecia que 
parte dos tributos seria destinado à Ancine para auxiliar no custeio de suas atividades, além do Programa de Apoio do Desenvolvimento Nacional do Cinema - PRODECINE, "atividades de fomento ao cinema e ao audiovisual desenvolvidas pelo Ministério da Cultura" e, por fim, ao Prêmio Adicional de Renda. Com as alterações trazidas pela Lei no 11.437/2006, os recursos da Condecine passaram a ser direcionados ao Fundo Nacional da Cultura - FNC, na categoria específica Fundo Setorial do Audiovisual - FSA. No tópico 3.3, demonstrou-se o direcionamento dos recursos ao segmento audiovisual, não havendo necessidade de se reprisar os fundamentos apresentados.

A destinação mostrou-se legítima. É perfeitamente possível que se direcione recursos da Condecine para o custeio das atividades da Ancine, como ocorreu até o advento da Lei no 11.437/2006. A agência reguladora não apenas regulamenta o mercado, mas promove políticas de incentivo (como concessão de prêmios e financiamentos), bem como fiscalização do respeito ao direito autoral, em linhas gerais, o que é de interesse de todo segmento. E, mesmo depois da referida lei, o direcionamento dos recursos permaneceu voltado ao incentivo do segmento, para a reforma de salas de exibição, aquisição de equipamentos de produção, financiamentos das obras, especialmente as de língua portuguesa e regionais. Estando clara a atuação da União, resta apenas a elucidação dos contribuintes definidos em lei e o respectivo vínculo com a atuação estatal.

Nas contribuições em exame, constatou-se que, quanto à Condecine Título, houve respeito à referibilidade indireta pelos contribuintes que promovem a "veiculação, a produção, o licenciamento e a distribuição de obras cinematográficas e videofonográficas com fins comerciais, por segmento de mercado a que forem destinadas", nos termos do art. 32, I da Medida Provisória $n^{\circ} 2.228-1 / 2001$. As obras audiovisuais, por definição do inciso I do art. 1ํ da Medida Provisória, correspondem ao "produto da fixação ou transmissão de imagens, com ou sem som, que tenha a finalidade de criar a impressão de movimento". A norma não regula qual deva ser o conteúdo expressado na obra, e apenas estabelece algumas isenções da Condecine sobre produção audiovisual jornalística e esportiva. Em precedente citado do Tribunal Regional Federal da $2^{2}$ Região, compreendeu-se que obras musicais compõem o grupo do audiovisual, sujeitando-se, portanto, ao pagamento da contribuição. Esse é o grupo tributado. 
Os contribuintes estão definidos no inciso I do art. 35 da medida provisória, quais sejam "detentor[es] dos direitos de exploração comercial ou de licenciamento no País". Nesse caso, a alíquota da Condecine é específica e devida por obra explorada em cada segmento de mercado. Há referibilidade indireta porque a atuação estatal financiada pela Condecine se direciona ao grupo de contribuintes ali tributado. Ao se incentivar a produção de obras audiovisuais, aquisição de equipamentos e reformas de salas de exibição, por exemplo, há atingimento de todo o segmento. Ainda que seja prestigiada a produção de obras regionais, de modo algum é possível sustentar que os detentores de direitos de obras estrangeiras não façam parte desse grupo. Em última análise, a arrecadação da Condecine financia a atuação estatal que concretização da Política Nacional do Cinema, que, por sua vez, afeta a atividade dos detentores dos direitos autorais de obras audiovisuais no Brasil.

Ainda no âmbito da Condecine Título, a medida provisória sujeita ao pagamento da contribuição as obras publicitárias nos segmentos de mercado, bem como as incluídas em programação internacional. O produtor ou o detentor do direito de licenciamento desse tipo de obra não é afetado pela atuação estatal, não está abrangido no grupo de indivíduos atingido pela Política Nacional do Cinema, prevista no art. $2^{\circ}$ da Medida Provisória, não são afetados indiretamente pela atuação estatal nesse setor, ao menos da maneira necessária para legitimar a incidência de uma contribuição especial, e, portanto, não se tem o respeito à referibilidade indireta nesse caso.

Outra contribuição estudada foi a Condecine Remessa, que incide à alíquota de onze por cento sobre o pagamento de rendimento de exploração de obra audiovisual no exterior, nos termos do art. 32, parágrafo único da medida provisória, cujo contribuinte é o "o responsável pelo pagamento, crédito, emprego, remessa ou entrega" conforme inciso III do art. 35. É certo que o titular do direito de exploração no Brasil que promove o pagamento ao exterior a título de rendimento dos direitos autorais pertence ao grupo afetado pela atuação estatal. Reafirma-se a referibilidade indireta como requisito de validade das Cides, bem como o respeito à referibilidade no caso da Condecine Remessa, para criticar o posicionamento do Conselho Administrativo de Recursos Fiscais de manter a dupla incidência da Condecine Remessa e Cide Royalties, pois não se constata a referibilidade indireta nessa segunda contribuição. O pagamento de rendimento por exploração de obra 
audiovisual não guarda relação com o desenvolvimento tecnológico brasileiro, nos termos do art. 1ํ da Lei no 10.168/2000.

Quanto à Condecine Teles, que nos termos do art. 32, II da Medida Provisória incide sobre "a prestação de serviços que se utilizem de meios que possam, efetiva ou potencialmente, distribuir conteúdos audiovisuais nos termos da lei que dispõe sobre a comunicação audiovisual de acesso condicionado", tem como contribuintes "as concessionárias, permissionárias e autorizadas de serviços de telecomunicações", conforme art. 34, IV. Tais serviços de comunicação são variados, abrangendo a prestação de Serviço Público Condicionado (TV por assinatura), Serviço Móvel Pessoal (telefonia celular), Serviço Telefônico Fixo Comutado e Serviço de Comunicação Multimídia. Apenas os prestadores do primeiro é que participam do grupo afetado pela atuação estatal. Isso porque a Lei de Acesso Condicionado estabelece que a produção, programação, distribuição e empacotamento são atividades do serviço de acesso condicionado, que guarda princípios comuns à Política Nacional do Cinema como "promoção da diversidade cultural e das fontes de informação, produção e programação", "promoção da língua portuguesa e da cultura brasileira" e o "estímulo à produção independente e regional", previstos no art. $3^{\circ}$. Esses prestadores de serviços de acesso condicionado estão inseridos no segmento do audiovisual como agentes efetivos, e a atuação estatal financiada pela Condecine Ihes é direcionada.

Por outro lado, as empresas de telefonia e comunicação multimídia, apesar de se relacionarem com o mercado audiovisual, dele não fazem parte. São empresas de telecomunicações que obtêm, de certa forma, vantagem pelo incremento e popularização das obras audiovisuais, o que também ocorre inversamente, o mercado audiovisual se beneficia do incremento dos meios de comunicação. Entretanto, apesar de ambos se privilegiarem dos respectivos desempenhos empresariais, a atuação estatal que concretiza a Política Nacional do Cinema não Ihes afeta da forma a autorizar a cobrança da Cide.

As razões que supostamente justificam a tributação dos serviços de telefonia e comunicação multimídia são esvaziadas quando se analisa a possibilidade de tributação dos próprios serviços de vídeo sob demanda, esses sim distribuidores de conteúdo audiovisual pela internet. São efetivos integrantes do segmento afetado, podendo sofrer intervenção da União em sua atividade, nos termos da lei, 
e devem arcar com a tributação correspondente. Como se apontou no trabalho, há estudos da Ancine pela tributação desses agentes e também um projeto de lei em trâmite na Câmara dos Deputados, de no 8.889/2017, que trata sobre a instituição da Condecine nesse segmento. 


\section{REFERÊNCIAS BIBLIOGRÁFICAS}

AGUILLAR, Fernando Herren. Direito Econômico: Do Direito Nacional ao Direito Supranacional, 5. ed. São Paulo: Atlas, 2016.

ALCÂNTARA, Rosana. VOD: nova fronteira de expansão para o audiovisual impactos, desafios e oportunidades. set/2016. 33 slides. Material apresentado no 44ㅇ Festival de Gramado em 2016. Disponível em: <https://www.ancine.gov.br/sites/default/files/apresentacoes/GRAMADO_Rosana \%20Alcantara.pdf> Acessado em 27/01/2018.

ALEXY, Robert. Teoría de los derechos fundamentales, 2. ed. Tradução: Carlos Beral Pulido. Madri: Centro de Estudios Politicos Y Constitucionales, 2012.

ALMEIDA, Cláudio Aguiar. O cinema brasileiro no Estado Novo: o diálogo com a Itália, Alemanha e URSS, Revista de Sociologia e Política, n. 12. São Paulo: USP p. 121-129, jun./1999.

ALMEIDA JUNIOR, Fernando Osorio de. Contribuição de Intervenção no Domínio Econômico. In: GRECO, Marco Aurélio. (Coord.). Contribuições de Intervenção no Domínio Econômico e Figuras Afins. São Paulo: Dialética, 2001.

AMARO, Luciano. Direito tributário brasileiro, 21. edição. São Paulo: Saraiva, 2016.

ARAGÃO, Alexandre Santos de. Agências Reguladoras e a Evolução do Direito Administrativo Econômico, 3. ed. Rio de Janeiro: Forense, 2013.

ASCENSÃO, José de Oliveira. Fundamento do direito autoral como direito exclusivo, SANTOS, Manoel Pereira dos. JABUR, Wilson Pinheiro. (Coord.). Série GVlaw: propriedade intelectual: Direito autoral. São Paulo: Saraiva, 2013.

ATALIBA, Geraldo. Hipótese de Incidência Tributária, 6. ed. São Paulo: Malheiros, 2009.

. Elementos de Direito Tributário. São Paulo: Revista dos Tribunais, 1978.

ÁVILA, Humberto. Sistema Constitucional Tributário, 5. ed. São Paulo: Saraiva, 2011.

Teoria dos Princípios. 14. ed. Malheiros: São Paulo, 2013.

A distinção entre princípios e regras e a redefinição do dever de proporcionalidade. Revista de Direito Administrativo, Rio de Janeiro, v. 215, p. 151179, jan./mar. 1999.

As Contribuições no Sistema Tributário Brasileiro. In: ROCHA, Valdir de Oliveira. (Coord.). Grandes Questões Atuais de Direito Tributário. São Paulo: Dialética, 2003. 
BAGATIN, Andreia Cristina. Captura das agências reguladoras independentes. São Paulo: Saraiva, 2013.

BALEEIRO, Aliomar. Direito Tributário Brasileiro. 11. ed. Atualização de: Misabel de Abreu Machado Derzi. Rio de Janeiro: Forense, 2003.

BARACHO, José Alfredo de Oliveira. Natureza Jurídica das Contribuições Sociais, Revista da Faculdade de Direito da Universidade de Minas Gerais, Belo Horizonte, n. 12, p. 91-121, out. 1972.

BARRETO, Aires Fernandino. Base de Cálculo, Alíquota e Princípios Constitucionais. São Paulo: Max Limonard, 1998.

. Curso de Direito Tributário Municipal. 2. ed. São Paulo: Saraiva, 2012.

BARRETO, Paulo Ayres. Contribuições: Regime Jurídico, Destinação e Controle, 2. ed. São Paulo: Noeses, 2006.

BARROS, Suzana Toledo de. O princípio da proporcionalidade e o controle de constitucionalidade das leis restritivas de direitos fundamentais. Brasília: Brasília Jurídica, 1996.

BARROSO, Luís Roberto. Curso de Direito Constitucional Contemporâneo. 4. ed. São Paulo: Saraiva, 2013.

A ordem econômica constitucional e os limites à atuação estatal no controle de preços, Revista de Direito Administrativo, Rio de Janeiro, v. 226, p. 187212, out. 2001.

- Intervenção do Estado no domínio econômico. Boletim de Direito Administrativo (BDA), São Paulo, v. 12, n. 4, p. 189-193, abr. 1996.

BASTOS, Celso Ribeiro. Curso de Direito Financeiro e de Direito Tributário. 5. ed. São Paulo: Saraiva, 1997.

Existe efetivamente uma Constituição econômica? Revista de Direito Constitucional e Internacional. São Paulo, v. 10, n. 39, p. 89-96, abr./jun. 2002.

BECKER, Alfredo Augusto. Teoria Geral do Direito Tributário, 6. ed. São Paulo: Noeses, 2013.

BERCOVICI, Gilberto. A Constituição e o papel do Estado no domínio econômico. Revista da Academia Brasileira de Direito Constitucional. Curitiba, v. 2, p. 117-129, 2002.

. Política Econômica e Direito Econômico. Revista da Faculdade de Direito da Universidade de São Paulo, São Paulo, v. 105, p. 309-406, 2010.

BONAVIDES, Paulo. Curso de Direito Constitucional. 6. ed. São Paulo: Malheiros, 1996. 
BORGES, José Souto Maior. Alterações procedidas na CF de 1988 pela Emenda Constitucional n. 33/2001. Contribuição de intervenção no domínio econômico. Lei n. 10.336/2001. In: SOUZA, Hamilton Dias de. (Coord.). Tributação Específica. São Paulo: Quartier Latin, 2007.

BRASIL. Agência Nacional do Cinema. Estudo Comparativo dos Preços dos Serviços de TV por Assinatura e Triple Play no Brasil e no Mundo em 2008, 2008.

BRASIL. Agência Nacional de Cinema, Consolidação da visão do Conselho Superior do Cinema sobre a construção de um marco regulatório do serviço de vídeo sob demanda, 2015. Disponível em: < https://www.ancine.gov.br/sites/default/files/CSC\%20\%20Consolida\%C3\%A7\%C3\%A30\%20Desafios\%20VoD\%2017\%2012\%2015_1. pdf $>$, acessado em 27/01/2018.

BRASIL. Agência Nacional do Cinema. Condecine - Valores Arrecadados por Mês - $2016 . \quad$ Disponível em: <https://oca.ancine.gov.br/sites/default/files/recursos_publicos/pdf/2908.pdf>. Acessado em 09 de janeiro de 2018.

BRASIL. Agência Nacional do Cinema. Relatório de Consulta Pública sobre a Notícia Regulatória sobre a Comunicação Audiovisual sob Demanda e Recomendações da ANCINE para uma regulação da Comunicação Audiovisual sob Demanda. Rio de Janeiro, 2017. Disponível em: <https://www.ancine.gov.br/sites/default/files/Vod\%20Documento\%20P\%C3\%BAb lico\%20Final\%20v3_2.pdf>. Acessado em 27/01/2017.

BRASIL. Ministério da Cultura. Ministério da Casa Civil. Ministério da Fazenda. Exposição de Motivos Interministerial no 04/2006. Brasília: 2006.

BRASIL. Ministério da Fazenda. Exposição de motivos do Ministro da Fazenda, Dr. Oswaldo Aranha, encaminhando ao Sr. Presidente da República o Projeto de Código Tributário Nacional. p. 1-548, 1954. Disponível em: < http://www2.senado.leg.br/bdsf/item/id/511517>. Acessado em 21/11/2017.

BRASIL. Ministério de Estado do Desenvolvimento, Indústria e Comércio. Ministério da Cultura. Exposição de motivos da Medida Provisória nº 2.219/2001. Disponível em:

<http://imagem.camara.gov.br/dc_20.asp?selCodColecaoCsv=J\&Datain=10/10/20 $01 \&$ txpagina $=21513 \&$ altura=700\&largura=800\#/> Acessado em 15/01/2018.

CAMARGOS, Luciano Dias Bicalho. Da Natureza Jurídica das Contribuições para o Instituto Nacional de Colonização e Reforma Agrária. São Paulo: MP Editora, 2006.

CANOTILHO, Joaquim José Gomes. Direito Constitucional e Teoria da Constituição. 7. ed. Coimbra: Almedina, 2003. 
CAPELATO, Maria Helena. Propaganda política e controle dos meios de comunicação. In: PANDOLFI, Dulce. (Org.). Repensando o Estado Novo. Rio de Janeiro: Fundação Getulio Vargas, 1999.

CARRAZZA, Roque Antonio. Curso de Direito Constitucional Tributário, 29. ed. São Paulo: Malheiros., 2013.

Contribuições de Intervenção no Domínio Econômico - Perfil Constitucional - Inexigibilidade da Contribuição para o Incra - Questões Conexas, Revista Dialética de Direito Tributário, n. 170, p. 93-128, nov. 2009.

CARVALHO FILHO, José dos Santos. Manual de Direito Administrativo, 31. ed. São Paulo: Atlas, 2017.

Estado Mínimo x Estado Máximo: o dilema. Revista Eletrônica sobre a Reforma do Estado (RERE), Salvador, n. 12, dez./jan./fev.2008. Disponível em: <http://www.direitodoestado.com.br/rere.asp>. Acesso em 10 de outubro de 2017.

Agências Reguladoras e Poder Normativo. In: ARAGÃO, Alexandre Santos. (Coord.). O Poder Normativo das Agências Reguladoras, 2. ed. Rio de Janeiro: Forense, 2011.

CARVALHO, Paulo Barros. Curso de direito tributário. 28. ed. São Paulo: Saraiva, 2017.

. Direito Tributário - Linguagem e Método, 3. ed. São Paulo: Noeses, 2009.

COÊLHO, Sacha Calmon Navarro. Curso de Direito Tributário Brasileiro, 15. ed. Rio de Janeiro: Forense, 2016.

MOREIRA, André Mendes. Inconstitucionalidades da Contribuição de Intervenção no Domínio Econômico Incidente sobre Remessas ao Exterior - CIDE Royalties, Revista Dialética de Direito Tributário, São Paulo, n. 89, p. 71-84, fev., 2003.

COMISSÃO DAS COMUNIDADES EUROPÉIAS. Directiva 2010/13/UE do Parlamento Europeu e do Conselho de 10 de Março de 2010, Estrasburgo, 2010. $<$ http://eur-lex.europa.eu/legal-

content/PT/TXT/HTML/?uri=CELEX:32010L0013\&from=EN> Acessado em 27/01/2019.

COMPARATO, Fabio Konder. Função Social da Propriedade dos Bens de Produção. Revista de Direito Mercantil, Industrial, Econômico e Financeiro, n. 63, p. 71-79, jul./set. de 1986.

COSTA, Ramon Valdés. Curso de Derecho Tributario. 2. ed. Buenos Aires: Depalma, 1996. p. 87.

CUNHA, Paulo César Melo da. Regulação Jurídica da Saúde Suplementar do Brasil. Rio de Janeiro: Lumen Juris, 2003. 
DERZI, Misabel. Contribuição para o Finsocial (parecer), Revista de Direito Tributário, São Paulo, v. 55, p. 194-222, 1992.

DI PIETRO, Maria Sylvia Zanella. Direito Administrativo, 30. ed. Rio de Janeiro: Forense, 2017.

ENDRES, Silvana Bussab. Contribuições de Intervenção no Domínio Econômico. In: GRECO, Marco Aurélio. (Coord.) Contribuições de Intervenção no Domínio Econômico e Figuras Afins. São Paulo: Dialética, 2001.

FALCÃO, Amílcar de Araújo, Direito Tributário Brasileiro. Rio de Janeiro: Financeiras, 1960. . Introdução ao Direito Tributário, 5. ed. Rio de Janeiro: Forense, 1994.

FERNANDES, Simone Lemos. Contribuições Neocorporativas na Constituição e nas Leis. Belo Horizonte: Editora Del Rey, 2005.

FERRAZ Jr., Tércio Sampaio. Introdução ao Estudo do Direito, 10. ed. São Paulo: Atlas, 2018.

FIGUEIREDO, Leonardo Vizeu. Lições de Direito Econômico. 9. ed. Rio de Janeiro: Forense, 2016.

FIGUEIREDO, Lucia Valle. Reflexões sobre a Intervenção do Estado no Domínio Econômico e as Contribuições Interventivas. In: As Contribuições no Sistema Tributário Brasileiro. (Coord. Hugo de Brito Machado). Dialética e ICET: São Paulo e Fortaleza, 2003.

FISCHER, Octávio Campos. A Escola Glorificadora da Finalidade: contribuições e reforma tributária. Revista do Centro de Estudos Judiciários, n. 22, p. 35-40, jul./set., 2003.

FURTADO, José de Ribamar Caldas. O problema da vinculação de recursos orçamentários. Revista do TCU, Brasília, n. 111, p. 63-72, jan./abr. 2008.

GAMA, Tácio Lacerda. Contribuição de intervenção no domínio econômico. São Paulo: Quartier Latin, 2003.

GIANNINI, Achille Donato. Instituciones de Derecho Tribuario. Traduzido por Sáinz de Bujanda. Madri: Editorial de Derecho Financiero, 1957.

GRAU, Eros. GRAU, Eros Roberto. A ordem econômica na Constituição de 1988. 9. ed. São Paulo: Malheiros, 2004.

; GUERRA FILHO, Willis Santiago (org.). Direito constitucional: estudos em homenagem a Paulo Bonavides. São Paulo: Malheiros, 2001.

GRECO, Marco Aurélio. Contribuições (uma figura sui generis). São Paulo: Dialética, 2000. 
. Contribuição de Intervenção no Domínio Econômico - Parâmetros para sua Criação. In: (Coord.). Contribuições de Intervenção do Domínio Econômico e Figuras Afins. Coord. São Paulo: Dialética, 2001.

. Contribuição de Intervenção no Domínio Econômico sobre "Royalties", Revista Dialética de Direito Tributário, n. 99, p. 133-151, dez. 2003.

. Em busca do controle sobre as Cides. Revista do Advogado, São Paulo, p. 101-118, 2007.

HARADA, Kiyoshi. Contribuições Sociais: Doutrina e Prática. São Paulo: Atlas, 2015.

HOFFMANN, Susy Gomes. As Contribuições no Sistema Constitucional Tributário. Campinas: Copola, 1996.

HORVATH, Estevão. Contornos da Contribuição de Intervenção no Domínio Econômico na Constituição de 1988. Tese de Livre-Docência. São Paulo: USP, 2008.

IVANOV, Debora. VoD - Consumo e regulação. 27/10/2017. 24 slides. Apresentação no Forum Mostra Internacional de Cinema de SP / FOLHA. Disponível em: $<$ https://www.ancine.gov.br/sites/default/files/apresentacoes/2017_10_27_Mostra \%20SP\%20-\%20VOD\%20-\%202017.pdf> Acessado em 27/01/2018.

JUSTEN FILHO, Marçal. Contribuições Sociais. Caderno de Pesquisas Tributárias. Contribuições Sociais, vol. 17, p. 149-170, 1992.

. Empresa, Ordem Econômica e Constituição. Revista de Direito Administrativo, Rio de Janeiro, n.212, p. 109-133, 1998.

LEOPOLDINO DA FONSECA, João Bosco. Direito Econômico. 3. ed. Rio de Janeiro: Forense, 2000.

LIMA, Heverton Souza. A Lei da TV Paga: impactos no mercado audiovisual. Dissertação de Mestrado apresentada à Escola de Comunicação e Artes da Universidade de São Paulo, 2015. p. 21-28. Disponível em: < http://www.teses.usp.br/teses/disponiveis/27/27161/tde-26062015162615/en.php>. Acessado em 17 de janeiro de 2018.

MACHAdO SEGUNDO, Hugo de Brito. Primeiras Linhas de Direito Tributário e Financeiro: Material e Processual, 8. ed. Atlas: São Paulo, 2014.

- Perfil Constitucional das Contribuições de Intervenção no Domínio Econômico. In: GRECO, Marco Aurélio. (Coord.). Contribuições de Intervenção no Domínio Econômico e Afins. São Paulo: Dialética, 2001.

MARQUES NETO, Floriano de Azevedo. Agências reguladoras independentes: fundamentos e seu regime jurídico. Belo Horizonhte: Forum, 2009. 
MARTINS, Ives Gandra da Silva. Controle Concentrado de Constitucionalidade e as Contribuições sobre Intervenção no Domínio Econômico. In: GRECO, Marco Aurélio. (Coord.). Contribuição de Intervenção no Domínio Econômico e Figuras Afins. São Paulo: Dialética, 2001.

MARTINS, Vinícius Alves Portela. Fundamentos da Atividade Cinematográfica e Audiovisual, 2. ed. Rio de Janeiro: Elsevier, 2012.

MÉLEGA, Luiz. Algumas reflexões sobre o regime jurídico das contribuições na Carta Política de 1998, Direito Tributário Atual. Revista Brasileira de Direito Tributário - RBDT. São Paulo, v. 11-12, p. 3291-3293, 1992.

MELLO. Celso Antônio Bandeira de. Curso de direito administrativo. 11. ed. São Paulo: Malheiros, 1998.

. O Estado de a Ordem Econômica. Revista de Direito Administrativo, Rio de Janeiro, v. 143, p. 37-50, 1981.

MELO, José Eduardo Soares. Contribuições Sociais no Sistema Tributário. 4. ed. São Paulo: Malheiros, 2003.

MENDES, Gilmar. Direitos fundamentais e controle de constitucionalidade: Estudos de Direito Constitucional. 4. ed. São Paulo: Saraiva, 2011.

MICHELI, Gian Antonio. Curso de Direito Tributário. Tradução de Marco Aurélio Greco e Pedro Luciano Marrey Jr. - São Paulo: Revista dos Tribunais, 1978.

MIRANDA, Francisco Cavalcanti Pontes de. Comentários à Constituição de 1967. São Paulo, Revista dos Tribunais, 1967, v. 2.

MIRANDA, Jorge. Manual de Direito Constitucional. 4. ed. Coimbra: Coimbra Editora, 2008.

MOREIRA NETO, Diogo de Figueiredo. Curso de direito administrativo. 11 ed. Rio de Janeiro: Forense, 1996.

MOREIRA, Egon Bockmann. O Direito Administrativo contemporâneo e a intervenção do Estado na ordem econômica. In: WAGNER JÚNIOR, Luiz Guilherme da Costa. (Org.). Direito Público: estudos em homenagem ao professor Adilson Abreu Dallari. Belo Horizonte: Del Rey, 2004.

Os princípios constitucionais da atividade econômica, Revista da Faculdade de Direito UFPR, vol. 45, p. 103-111, 2006.

NEVES, Marcelo. Entre hidra e Hércules: princípios e regras constitucionais. São Paulo: Martins Fontes, 2013.

NUSDEO, Fábio. Curso de Economia: Introdução ao Direito Econômico. 3. ed. São Paulo: Revista dos Tribunais, 2001. 
OLIVEIRA, Fábio Corrêa Souza de. Por uma teoria dos princípios: o princípio constitucional da razoabilidade. Rio de Janeiro: Lumen Juris, 2003.

OLIVEIRA, José Marcos Domingues. Contribuição ao Sebrae - Questões polêmicas e recentes desdobramentos jurisprudenciais. In: GRECO, Marco Aurélio. (Coord.). Contribuições de Intervenção no Domínio Econômico e Figuras Afins. São Paulo: Dialética, 2001.

. O controle do desvio de finalidade das contribuições, Revista Tributária e de Finanças Públicas, v. 75, p. 103-144, jul./ago. 2007.

OLIVEIRA, Regis Fernandes. Curso de Direito Financeiro, 7. ed. São Paulo: Revista dos Tribunais, 2015.

OLIVEIRA, Ricardo Mariz de. Contribuições de Intervenção no Domínio Econômico - Concessionárias, Permissionárias e Autorizadas de Energia Elétrica - "Aplicação" obrigatória de Recursos (Lei 9.991). In: GRECO, Marco Aurélio. (Coord.). Contribuições de Intervenção no Domínio Econômico e Figuras Afins. São Paulo: Dialética, 2001.

OLIVEIRA, Yonne Dolacio de. Contribuições Especiais - Noções Gerais Contribuição de intervenção no Domínio Econômico. Cadernos de Direito Tributário e de Finanças Públicas, São Paulo, n. 12, jul./set. 1995.

OSÓRIO, Fábio Medina. Direito Administrativo Sancionador. São Paulo: RT. 2000.

PAIVA, André Ricardo Noborikawa. ROSSI, Carla. CHIAVENATO, Daniele. BRASIL, Eric. GUEDES FILHO, Ernesto Moreira. O impacto econômico no setor audiovisual brasileiro. São Paulo: Motion Picture Association - America Latina (MPA-AL), 2016. Disponível em: <http://www.mpaamericalatina.org/wpcontent/uploads/2016/10/mpa_sicav_2016.pdf> acessado em 27/01/2018.

PALMA, Freitas. História do direito, 6. ed. São Paulo: Saraiva, 2017.

PAULSEN, Leandro. VELLOSO, Andrei Piten. Contribuições: Teoria Geral e Contribuições em Espécie. 2. ed. Porto Alegre: Livraria do Advogado, 2010.

PIMENTA, Paulo Roberto Lyrio. Perfil Constitucional das Contribuições de Intervenção no Domínio Econômico. In: GRECO, Marco Aurélio. (Coord.). Contribuições de Intervenção no Domínio Econômico e Figuras Afins. São Paulo: Dialética, 2001.

. As normas constitucionais programáticas e a reserva do possível. Revista de Informação Legislativa, v. 193, p. 7-20, 2012.

Significado e importância da vinculação das receitas das contribuições especiais. In: ROCHA, Valdir de Oliveira. (Coord.). Grandes Questões Atuais do Direito Tributário. São Paulo: Dialética, 2004. v. 4. 
PISCITELLI, Tathiane dos Santos. Uma proposta harmonizadora para o tema da destinação: análise a partir do PIS e da Cofins. In: Instituto Brasileiro de Estudos Tributários (Org.). Direito Tributário, Linguagem e Método: as grandes disputas entre jurisprudência e dogmática na experiência brasileira atual. São Paulo: Noeses, 2008.

. O dever das teles de financiar o cinema brasileiro. JOTA. 2016. Disponível em: < https://www.jota.info/opiniao-e-analise/artigos/o-dever-das-teles-definanciar-o-cinema-brasileiro-27022016>. Acessado em 17 de janeiro de 2018.

PONTES, Helenilson Cunha. O Princípio da Proporcionalidade e o Direito Tributário. São Paulo: Dialética, 2000.

RIBEIRO, Ricardo Lodi. O princípio da capacidade contributiva nos impostos, nas taxas e nas contribuições parafiscais. Revista Fórum de Direito Tributário - RFDT, Belo Horizonte, ano 8, n. 46, jul./ago. 2010. Disponível em: $<$ http://www.bidforum.com.br/PDI0006.aspx?pdiCntd=68930 . Acesso em: 1 nov. 2017.

ROCHA, Valdir de Oliveira. Empresas sem empregados e Contribuições de Seguridade Social. In:

São Paulo: Dialética, 1995. (Org.). Contribuições Sociais: Questões Polêmicas.

SANTI, Eurico Marcos Diniz de. As classificações no Sistema Tributário Brasileiro. In Justiça Tributária: direitos do Fisco e garantia dos contribuintes nos atos da administração e no processo tributário. I Congresso Internacional de Direito Tributário. Instituto Brasileiro de Estudos Tributários - IBET. São Paulo: Max Limonad, 1998.

SCAFF, Fernando Facury. As Contribuições Especiais e o Princípio da Afetação, Revista Dialética de Direito Tributário, São Paulo, n. 98, p. 44-62, nov. 2003.

SCHOUERI, Luís Eduardo. Direito tributário, 7. ed. São Paulo: Saraiva, 2017.

. Algumas Considerações sobre a Contribuição de Intervenção no Domínio Econômico no Sistema Constitucional Brasileiro. A Contribuição ao Programa Universidade-Empresa. In: GRECO, Marco Aurélio. (Coord.). Contribuições de Intervenção no Domínio Econômico e Afins. São Paulo: Dialética, 2001.

Royalties e Assistência Técnica ao Exterior - Exigências da CIDE. Revista de Estudos Tributários, Porto Alegre, v. 7, n.37, p. 144-162, 2004.

Forense, 2005.

Normas tributárias indutoras e intervenção econômica. Rio de Janeiro:

. CEZAROTI, Guilherme. A Cide-royalties e as Remessas por Licença de Distribuição e Comercialização de Programas de Computador, Revista Dialética de Direito Tributário, n. 130, p. 41-55, jul. 2006. 
SILVA, José Afonso da. Curso de Direito Constitucional Positivo. 37. ed. São Paulo: Malheiros, 2014.

SILVA, Luana Maira Rufino Alves da. Estudo do formato de taxação do VOD. 27/10/2017. 32 slides. Apresentação no Grupo de Trabalho de VOD do Conselho Superior de Cinema. Disponível em: <https://www.ancine.gov.br/sites/default/files/apresentacoes/GT\%20VoD\%20Luan a\%20Panorama\%20Internacional.pdf> Acessado em 27/01/2018.

SOARES, Murilo Rodrigues da Cunha. Microempresas: Tributação inadequada e evasão fiscal. Tributação em Revista. Brasília, v. 3, n. 8, abr./jun. p. 15-20, 1994.

SOUSA, Rubens Gomes de. Compêndio de legislação tributária. São Paulo: Resenha Tributária, 1975.

SOUZA, Hamilton Dias de. Finsocial. Dois impostos; um do campo residual, outro do imposto de renda: violação do princípio da anterioridade. Direito Tributário Atual, v. I, p. 87-144, 1982.

. Contribuições Especiais. In: MARTINS, Ives Gandra da Silva. (Coord.). Curso de Direito Tributário. 14. ed. São Paulo: Saraiva, 2012.

SOUZA, Pedro Bastos de. A lei do serviço de acesso condicionado como instrumento de fomento à produção audiovisual brasileira. In: $X$ Encontro de estudos multidisciplinares em cultura, 2014, Salvador-BA. Anais do X ENECULT Políticas Culturais, v. 1. Salvador: UFBA, p. 1-15, 2014.

SURREY, Stanley S. Tax Incentives as device for implementing government policy: a comparison with direct government expenditures. Harvard Law Review, v. 83, n. 4, p. 705-738, fev. 1970.

TÁCITO, Caio. O princípio da razoabilidade das leis. In: TÁCITO, Caio. (Coord.). Temas de direito público. Rio de Janeiro-São Paulo: Renovar, 1997.

TÔRRES, Heleno Taveira. Pressupostos Constitucionais das Contribuições de Intervenção no Domínio Econômico. A CIDE-Tecnologia. In: ROCHA, Valdir de Oliveira. (Coord). Grandes questões atuais do Direito Tributário. São Paulo: Dialética, 2003, v.7.

TORRES, Ricardo Lobo. Tratado de direito constitucional financeiro e tributário. Rio de Janeiro: Renovar, 2007. v. 4.

VELLOSO, Andrei Pitten. PAULSEN, Leandro. Contribuições: Teoria Geral e Contribuições em Espécie. 2. ed. Porto Alegre: Livraria do Advogado, 2010.

XAVIER, Alberto. ELMERY, Renata. A inaplicabilidade da Cide - Remessas aos Contratos de Licenciamentos de Filmes. In: SOUZA, Arivaldo Santos de. SANTOS, Guilherme. MACHADO, Hugo de Brito. MARTINS, Ives Gandra da Silva. (Coord.). Direito Tributário: Estudos avançados em homenagem a Edvaldo Brito. São Paulo: Atlas, 2014. 
YAMASHITA, Douglas. Direito Tributário: uma visão sistemática. São Paulo: Atlas, 2014. 